Dulmen, A.M. van, Verhaak, P.F.M., Bilo, H.J.G. Shifts in doctor-patient communication during a series of outpatient consultations in non-insulin-dependent diabetes mellitus. Patient Educatien and Counseling: 1997, 30(3), 227-237

\begin{tabular}{|l|l|}
\hline $\begin{array}{l}\text { Postprint } \\
\text { Version }\end{array}$ & 1.0 \\
\hline Journal website & $\underline{\mathrm{http}: / / \text { www.pec-journal.com/article/S0738-3991\%2896\%2900965-2/abstract }}$ \\
\hline Pubmed link & $\underline{\text { http://www.ncbi.nlm.nih.gov/pubmed/9104379 }}$ \\
\hline DOI & $10.1016 / \mathrm{S} 0738-3991(96) 00965-2$ \\
\hline
\end{tabular}

This is a NIVEL certified Post Print, more info at http://www.nivel.eu

\title{
Shifts in doctor-patient communication during a series of outpatient consultations in non-insulin- dependent diabetes mellitus
}

\author{
ALEXANDRA M. VAN DULMENA*, PETER F.M. VERHAAKª HENK J.G. BILO
}

${ }^{a}$ NIVEL (Netherlands Institute of Primary Health Cure), P.O. Box 1.568. 3500 BN Utrecht. The Netherlands bHospital de Weezenlanden. Zwolle, The Netherlands

*Corresponding author. Tel.: + 31302319946 , fax: + 31302319290.

\begin{abstract}
As the treatment of non-insulin-dependent diabetes mellitus (NIDDM) largely depends on self-management, patient compliance and satisfaction, diabetes specific beliefs and fears need special consideration during medical consultations by means of effective communication. Communication patterns are likely to change through time. For that reason, the first three consultations between 18 newly referred patients with poorly controlled NIDDM and their medical specialist were videotaped. Subsequently, changes in doctor's and patients' verbal and nonverbal communication behaviours during these 54 consultations were analysed. Furthermore, an investigation was carried out to distinguish those communication behaviours most strongly related to patient satisfaction. Findings suggest that the first consultation is most important for building an effective doctor-patient relationship, the second for discussing treatment matters, and the third for addressing psychosocial issues. Further research incorporating clinical outcome measures is recommended to determine which were the behaviours with the greatest influence on patient health outcome.
\end{abstract}

\section{INTRODUCTION}

It is generally accepted that, in non-insulin-dependent diabetes mellitus (NIDDM), compliance with regimens directed towards improved metabolic control is important in preventing the development of complications (e.g. nephropathy, retinopathy, foot problems) $[1,2]$. The efficacy of treatment largely depends on patients' knowledge, skill, and motivation; factors which can all be influenced effectively by communication with specialized health care providers. Conversely, difficulties in communicating with the patient are an important cause of inefficacy of the treatment of NIDDM [3]. Attention to communication between doctors and patients is also recommended, because this is likely to reveal appropriate methods in diabetes-education 141, tailored to patients' individual needs [5].

Patients have two needs which correspond with the demands of treatment: the need for medical information and instruction and the need for emotional support and reassurance [6]. These needs correspond with two types of doctor behaviour: instrumental behaviour for 
Dulmen, A.M. van, Verhaak, P.F.M., Bilo, H.J.G. Shifts in doctor-patient communication during a series of outpatient consultations in non-insulin-dependent diabetes mellitus. Patient Educatien and Counseling: 1997, 30(3), 227-237

giving information and advice, and affective behaviour for showing concern and giving emotional support [7]. Affective communication can be conveyed both verbally and nonverbally. In NIDDM, diabetes-specific health beliefs and fears, such as beliefs about the benefits of treatment, attributions to personal diabetes control and fear of hospitalisation, are known to influence adherence to doctors' instructions [8-10]. Moreover, diabetes has a strong impact on patients' life and, at the same time, stress, anxiety, and neuroticism can deregulate diabetes [11-13]. Consequently, affective communication which focuses on the meaning of the disease for the patient and instrumental communication giving clear information necessary to alter dysfunctional beliefs will both be important in the treatment of NIDDM.

The rationale underlying this line of reasoning was inferred from a theoretical framework for research into doctor-patient communication recently proposed by Ong et al. [14], in which background, process and outcome variables are brought together (Fig. 1).

Fundamental in this framework are the background variables that have been shown to affect communication behaviours, which in turn were found to influence patient outcomes. In this article, the framework will be applied to communication between a medical specialist and patients with NIDDM.

One additional element which has been largely ignored in research into doctor-patient communication will be attended to specifically in this article, namely the influence of the rank order of the consultation in newly referred patients on doctor-patient communication. Referred, poorly controlled NIDDM patients need several visits to the specialist to adjust their treatment. Examining the content of just one consultation would only cover a part of the process of management. A much greater part of the communication process can be visualized by investigating three consecutive outpatient consultations. Presumably, doctor and patient communication styles are not static, but change in time. Research findings indeed show that patients' information-seeking behaviour differs between first and subsequent visits $[15,16]$. Such data are lacking with respect to patient needs for emotional support and psychosocial counseling. It may be hypothesized that at first patients' uncertainty and anxiety require doctors' emotional support and attention, whereas, in subsequent visits, patients might need more medical-technical information to apply the new treatment methods effectively. Adequate management of the condition is likely to require doctors to respond to these changing needs accordingly, by shifting their communication style [17].

In this article the following research questions were addressed specifically:

1. Do the communication styles of the doctor and his patients with poorly controlled NIDDM change during a series of outpatient consultations?

2. What are the specific aspects in the communications related to patient satisfaction with the outpatient visits?

3. What is the relationship between verbal and nonverbal communication behaviours?

\section{[FIGURE 1]}

\section{METHODS}

\subsection{Subjects}

This article focuses on patients with NIDDM who are referred to the outpatient clinic for internal medicine because diet and antidiabetic agents can no longer adequately control their diabetes. Eighteen consecutive patients with poorly controlled NIDDM were asked permission to videotape their first three consultations with one male internist at an outpatient clinic for internal medicine. In this outpatient clinic internist, diabetes nurse, and dietitian work closely together. Newly referred patients first attend the internist for diagnostic procedures and physical examination. Subsequently, patients visit the nurse and the dietitian for behavioural instructions about self-management and food intake. The present study 
Dulmen, A.M. van, Verhaak, P.F.M., Bilo, H.J.G. Shifts in doctor-patient communication during a series of outpatient consultations in non-insulin-dependent diabetes mellitus. Patient Educatien and Counseling: 1997, 30(3), 227-237

focuses exclusively on the dyadic consultations between the patient and the internist. All patients gave written consent for the recording, which took place with a videocamera positioned in a corner of the room. There were five male and thirteen female patients, with mean ages of 60 (S.D. 11) and 64 (S.D. 8) years, respectively (ns). ,4t the end of the three consultation period, one third of the patients had switched to insulin therapy.

\subsection{Analysis of communication}

The verbal and nonverbal communication between internist and patient was measured by two independent raters directly from the videorecordings.

\subsubsection{Verbal behaviour}

Doctor-patient communication during the 54 consultations was measured by the Roter Interaction Analysis System (RIAS) [18], which is specially designed to code both doctor and patient communication. This system distinguishes instrumental or task-related and affective or socio-emotional verbal utterances in doctors and patients. Based on the findings from an earlier study [19], the categories were reduced to 16 clusters, identical for specialist and patient. Instrumental clusters refer to those communication aspects which primarily focus on solving problems, such as giving information, asking questions, and counseling. Affective clusters refer to those aspects needed to establish a therapeutically effective relationship between doctor and patient, such as giving comfort and reassurance and showing empathy, optimism, concern and understanding. The average interrator-reliability (Pearson's r) for these clusters appeared to be 0.82 for patient utterances $(0.77$ and 0.85 for affective and instrumental utterances, respectively) and 0.78 for specialist utterances $(0.80$ and 0.77 for affective and instrumental utterances, respectively) [20]. T o control for potential differences in lengths of visits, categories were divided by the total number of utterances. In addition to the non-overlapping RIAS categories, the duration of the speaking time for doctor and patient, of the physical examination, and of extra-consultation interruptions, such as telephone calls, were registered and adjusted for consultation length. Furthermore, patientcentredness [21] was measured using two five-point Likert scales indicating the extent in which the specialist took the patient's views into consideration in the diagnostic and therapeutic phases of the consultation. All consultations were systematically observed using the CAMERA computer system, which is especially designed for coding behavioural interactions from video recordings [22]. The conversation during physical examination, which took place in a separate room, was excluded from analysis.

\subsubsection{Nonverbal behaviour}

The general affective impression of doctor's and patients' communication was rated on four six-point rating scales, measuring irritation, nervousness, interest, and warmth [1\&19]. Patient-directed gaze, that is the time the doctor looked directly into the patient's face, was measured and adjusted for the time the doctor was in sight. Camera angles did not permit coding of eye gaze for the patient.

\subsection{Patient satisfaction}

Following each outpatient consultation, patients completed the Medical Interview Satisfaction Scale (MISS) which consist of 26 items in a five-point Likert-type format ('strongly agree' to 'strongly disagree') [23]. This scale measures three aspects of patient satisfaction: cognitive (nine items; Cronbach's $\alpha=0.82$ ) affective (nine items; $\alpha=0.73$ ) and behavioural (eight items; $\alpha=0.75$ ) satisfaction. Cognitive items refer to the doctor's giving explanations and information and the patient's understanding of diagnosis, etiology, 
Dulmen, A.M. van, Verhaak, P.F.M., Bilo, H.J.G. Shifts in doctor-patient communication during a series of outpatient consultations in non-insulin-dependent diabetes mellitus. Patient Educatien and Counseling: 1997, 30(3), 227-237

prognosis, and effects of treatment. Affective items describe the doctor's warmth and the patients' feelings of trust, confidence, and freedom to express themselves. Behavioural items measure the patient's evaluation of the doctor's professional behaviour, physical examination, diagnostic procedures, and treatments. The scale was scored by summing the scores for the subscales and dividing by the number of responses for each subscale.

\subsection{Statistics}

Changes in communication behaviour through time were investigated by means of one-way analysis of variance, Duncan's multiple range test for pairwise comparisons of group means, and t-test when appropriate. These changes were examined with respect to each RIAS category separately and also after RIAS categories were merged in an instrumental and an affective cluster. As patients were asked to complete the MISS after each consultation, it was possible to examine the relationships between the level of satisfaction and the nature of doctor-patient communication during the previous consultation in all 54 consultations separately. The three consultations were combined to investigate the relationship between verbal and nonverbal communication behaviour. Relationships were examined by means of Pearson's correlation.

\section{RESULTS}

\subsection{General consultation characteristics}

As shown in Table 1, initial outpatient visits were, on average, significantly longer than subsequent visits $(\mathrm{F}=79.64, \mathrm{P}<0.0001)$. Consistent with this, significantly more utterances were made during the initial consultation $(\mathrm{F}=50.29, \mathrm{P}<0.0001)$, also when broken down by interactant.

Adjusted for the consultation length, the doctor spoke longer than the patients during the repeat visits $(\mathrm{t}=6.54 . \mathrm{P}<0.0001$ and $\mathrm{t}=2.93, \mathrm{P}<0.01$, respectively), but not during the first visit. Furthermore, around $6 \%$ of each consultation was taken up by extra-consultation interruptions. Table 1 furthermore shows that the amount of time the doctor looked at the patient declined gradually from initial to third consultation $(\mathrm{F}=9.75, \mathrm{P}=<0.001)$. Pairwise comparisons between consultations revealed that the significant differences in consultation characteristics could all be attributed to differences in consultation means between the first and second consultations, as well as between the first and third. Apart from that, the proportion of doctor speaking time and of patient-directed gaze were also found to differ significantly between the second and third consultations.

\section{[TABLE 1]}

\subsection{General communication behaviours}

In order to get an impression of the overall changes in the proportion of affective and instrumental behaviours, changes in the general affective and instrumental category totals were considered first (Table I). During each consultation, the majority of doctor utterances were instrumental, whereas, in patients, only during the first consultation did the number of instrumental utterances exceed the number of affective utterances $(t=9.38, \mathrm{P}<0.0001)$. Comparisons between doctor and patient speech revealed that, during the first consultation, doctor and patient did not differ in the proportion affective or instrumental utterances. During the second consultation, the doctor made significantly more instrumental utterances than patients ( $44 \%$ and $19 \%$, respectively; $\mathrm{t}=11.52, \mathrm{P}<0.0001)$ and patients made more affective utterances than the doctor $(22 \%$ and $15 \%$, respectively: $\mathrm{t}=-4.70, \mathrm{P}<0.0001)$. 
Dulmen, A.M. van, Verhaak, P.F.M., Bilo, H.J.G. Shifts in doctor-patient communication during a series of outpatient consultations in non-insulin-dependent diabetes mellitus. Patient Educatien and Counseling: 1997, 30(3), 227-237

Finally, during the third consultation, the proportion of affective utterances did not differ between doctor and patient, whereas the doctor made significantly more instrumental utterances than the patients $(38 \%$ and $20 \%$. respectively; $\mathrm{f}=5.78, \mathrm{P}<0.0001)$. Pairwise comparisons between consultations revealed that, except for the proportion affective utterances by the doctor, these differences could all be attributed to differences in means of consultation between the first and second consultations as well as between the first and third consultations. In addition, the proportion of affective and instrumental utterances made by the doctor were (also) found to differ significantly between the second and third consultations.

\subsection{Specific doctor communication behaviours}

A closer look at the doctor communication behaviours during each consultation is presented in Table 2. An examination of doctor's verbal affective behaviours revealed that during the first outpatient consultation the doctor was more attentive, as he expressed significantly more agreement and gave more paraphrases than during subsequent visits. In addition to this, during subsequent consultations the doctor showed more optimism regarding physical or emotional aspects of the condition by giving more reassurance. In addition, the doctor gave more consideration to patient views on therapeutic issues during subsequent visits, as was demonstrated by an increase in the level of patient-centredness in the therapeutic phase. Significantly more medical questions were asked during the first consultation with respect to doctor's instrumental behaviour, whereas the proportion of medical information and medical counseling was higher in both subsequent visits. No significant differences were found between the three consultations in the scores on the affect scales (Table 2). Pairwise comparisons between consultations showed that all significant differences resulted from differences between the first and second consultations. Differences in the proportions paraphrases, reassurances, medical questions, medical information, medical counseling, and patient-centredness during the therapeutic phase were also significant between the first and third consultations. Additionally, differences in the proportion of reassurance, requests for clarification, and medical information were also significant between the second and third consultations.

\section{[TABLE 2]}

\subsection{Specific patient communication behaviours}

A focus on patients' verbal affective behaviours revealed that during the first consultation, patients appeared to be less attentive towards the doctor, as they directed fewer agreements and paraphrases to the doctor than during subsequent consultations (Table 3). Patients' positive statements, as measured by the proportion reassurances, gradually increased over time comparably, in fact, with doctor communication. With respect to instrumental communication, patients gave more medical as well as psychosocial information and asked fewer medical questions during the first consultation than during subsequent consultations. No significant differences were found between the three consultations in the scores on the affect scales (Table 3). All significant differences between consultations resulted from differences between the first and second consultation. Moreover, differences between the proportion of agreements, medical questions, and medical information were also significant between the first and third consultations.

\section{[TABLE 3]}


Dulmen, A.M. van, Verhaak, P.F.M., Bilo, H.J.G. Shifts in doctor-patient communication during a series of outpatient consultations in non-insulin-dependent diabetes mellitus. Patient Educatien and Counseling: 1997, 30(3), 227-237

\subsection{Patient satisfaction}

Completed satisfaction questionnaires were obtained with respect to 44 consultations $(81 \%)$. As satisfaction scores did not differ between consultations and patient satisfaction ratings were overall very positive (Table 4 ), consultations were grouped as extremely satisfactory or not (dichotomized at the median) and subsequently compared. First, consultations in which doctor's cognitive performance was evaluated as extremely satisfactory $(\mathrm{N}=25)$ were compared with less satisfactory consultations $(\mathrm{N}=19)$. This comparison showed that the doctor gave proportionally more orientations $(\mathrm{P}<0.05)$ more paraphrases $(\mathrm{P}<0.05)$ and fewer reflections $(\mathrm{P}<0.01)$ in extremely satisfactory consultations. The comparison between consultations judged extremely satisfactory regarding doctor's affective performance $(\mathrm{N}=20)$ as against those judged less satisfactory $(\mathrm{N}=24)$ showed that the doctor was less irritated $(\mathrm{P}<0.05)$ and more interested $(\mathrm{P}<0.05)$ in consultations considered extremely satisfactory. Moreover, in extremely satisfactory consultations the doctor expressed proportionally fewer concerns $(\mathrm{P}<.05)$ and the patients asked for clarification less frequently $(\mathrm{P}<0.05)$. Finally, in consultations evaluated as extremely satisfactory, the doctor tended to be more patient-centred during the diagnostic phase $(\mathrm{P}<0.10)$. With respect to doctor's behavioural performance, in extremely satisfactory consultations $(\mathrm{N}=22)$ patients appeared to express proportionally more optimistic utterances $(\mathrm{P}<0.05)$ than in less satisfactory consultations $(\mathrm{N}=22)$. Moreover, both groups of consultations differed at the level of a statistical trend with respect to the duration of the physical examination (PC 0.10) which was twice as long in extremely satisfactory consultations, and also in the proportion of social talk which was smaller in extremely satisfactory consultations $(\mathrm{P}<0.10)$.

Additional comparisons per consultation revealed that when the doctor showed more social behaviour and less irritation during the first consultation patients were more likely to be extremely satisfied with his cognitive and affective performance $(\mathrm{P}<0.05$ for both variables). During the second consultation a higher level of interest shown by the doctor as well as a higher level of patient-centredness during the therapeutic phase contributed to extreme satisfaction regarding doctor's cognitive and affective performance $(\mathrm{P}<0.01$ and $\mathrm{P}$ $<0.05$, respectively). Finally, when the doctor gave more orientations and psychosocial counseling and showed fewer concerns during the third consultation, the consultation was more likely to be assessed as extremely satisfactory with respect to doctor's cognitive and affective performance $(\mathrm{P}<0.01, \mathrm{P}<0.05$ and $\mathrm{P}<0.05$, respectively).

\section{[TABLE 4]}

\subsection{Relationships between verbal and nonverbal behaviours}

Significant positive correlations were found between the proportion of patient-directed gaze and the proportion of psychosocial information given by both doctor $(\mathrm{Y}=0.48, \mathrm{P}<0.001)$ and patient $(\mathrm{r}=0.43, \mathrm{P}<0.01)$, i.e. the more the doctor looked at the patient, the more psychosocial information was exchanged. Significant negative correlations were found between the proportion of patient-directed gaze and the proportion of agreements indicated by the patient $(\mathrm{r}=-0.35, \mathrm{P}<0.05)$ as well as the proportion of reassurance $(\mathrm{Y}=-0.30, \mathrm{P}<$ $0.05)$ orientations $(\mathrm{I}=-0.38, \mathrm{P}<0.01)$, and medical counseling $(\mathrm{r}=-0.42, \mathrm{P}<0.01)$ from the doctor. So, when the doctor looked at the patient, the patient indicated less agreement. Furthermore, the more the doctor looked at the patient, the less he made reassuring comments, told the patient what was about to happen, and gave medical advice.

\section{DISCUSSION}


Dulmen, A.M. van, Verhaak, P.F.M., Bilo, H.J.G. Shifts in doctor-patient communication during a series of outpatient consultations in non-insulin-dependent diabetes mellitus. Patient Educatien and Counseling: 1997, 30(3), 227-237

The aim of this explorative study was to examine whether doctor's and patient's verbal and nonverbal communication behaviours change during a series of consecutive outpatient consultations in NIDDM. Findings suggest that communication patterns do indeed change. During the initial visit the proportion of speaking time as well as the proportion of affective and instrumental utterances did not appear to differ between doctor and patient. In subsequent visits, however, doctor's speech predominated and this predominant communication appeared to be primarily instrumental, whereas patient communication was mostly affective. At the same time, the proportion of patient-directed gaze had decreased when compared with the first consultation. These results seem to indicate that during the initial outpatient consultation the doctor-patient interaction is more equal and reciprocal, both necessary conditions for building an effective interpersonal relationship based on trust and capable of influencing patients' health behaviour [24,25]. Conversely, the findings also suggest that once the doctor-patient relationship has been established, less effort is put into maintaining it. The observed lack of congruency between doctor and patient in subsequent visits might engender, however, a risk of overlooking important cues, such as psychosocial issues like patient needs and concerns, which are known to be related to the compliance and general well-being of the oIder patient with NIDDM [12]. As psychosocial issues are less frequently raised with older than with younger patients and doctors appear to be less responsive to psychosocial issues raised by older patients, doctors should be especially careful in this matter [26]. Recently, in general practice consultations, the information interchange on psychosocial topics was found to be positively related to the level of patientdirected gaze [27]. In the present study, these findings were replicated for outpatient practice, which may either stress the impact of this nonverbal tool or merely reflect doctor's tendency to look at the patient more frequently when psychosocial issues are discussed. It was hypothesized beforehand that during the initial consultation communication would be primarily affective, whereas, in subsequent consultations, communication would become more instrumental. In general, these hypotheses were confirmed in this study.

A remarkable finding is that, although in the present study repeat consultations seemed less balanced than initial ones, this imbalance was not reflected in a decrease in patient satisfaction scores nor in changes in the scores on the affect scales as parameters for the affective impression of the consultation. Apparently, patients were not bothered by the observed shifts in communication patterns, perhaps because the doctor-patient relationship was already firmly established in the initial consultation. Another explanation is that patients, and especially older ones, are generally known to report high levels of satisfaction with the specialist to convey their feelings of gratitude [28,29]. Nevertheless, on the basis of patient satisfaction scores, consecutive consultations can roughly and tentatively be characterized in terms of patients' most highly valued communication parameters. This categorization shows that patients especially value doctor's social behaviour during the first consultation, patient-centredness with respect to therapeutic issues during the second consultation, and psychosocial counseling during the third consultation. This might imply that, in order to increase the level of patient satisfaction with outpatient consultations, building a doctor-patient relationship should indeed be the primary purpose of the first consultation. negotiating treatment matters might be an important issue of the second consultation, and additional psychosocial issues might have to be addressed specifically in the third consultation [29]. These alleged differences between consecutive outpatient consultations are in conformity with differences between consecutive sessions in physical therapy. The first physical therapy session appears to be devoted to giving information, the second session is focused at behavioural instructions, whereas in subsequent sessions psychosocial issues become the subject of discussion [30].

Interestingly, inverse relationships were found between, on the one hand, the proportion patient- directed gaze and, on the other hand, the proportion agreements by the patients and the proportion reassurance, orientations and medical advice from the doctor. Possibly, these findings indicate a trade-off between these nonverbal and verbal behaviours. Patient-directed 
Dulmen, A.M. van, Verhaak, P.F.M., Bilo, H.J.G. Shifts in doctor-patient communication during a series of outpatient consultations in non-insulin-dependent diabetes mellitus. Patient Educatien and Counseling: 1997, 30(3), 227-237

gaze might convey persuasive messages which can also by transmitted verbally by encouragement. orientations, and advice. In like manner, when the doctor looks at the patient, it may be less important for the patient to communicate his/her agreements verbally. Further research using video recordings in clinical settings is needed to confirm these tentative conclusions.

Previously, in general practice a methodical approach was valued most highly in initial consultations, whereas patient-centredness with respect to treatment regimens was valued highly during subsequent visits [19]. In the present outpatient setting, these differences are comparable: during the first consultation doctors asked a lot of questions and patients gave a lot of information. At the same time, doctors encouraged patient speech by signalling attentive listening. In addition, in subsequent consultations, the doctor appeared to allow the patient to discuss treatment matters more. This is very important because the adherence to treatment is known to increase when the treatment for diabetes mellitus is adapted to patients' needs and life circumstances [31]. In this respect, caution is advised so as not to confuse patients' desire to discuss treatment matters with his desire to make treatment decisions, because generally doctors tend to underestimate the first and overestimate the latter [32].

Some methodological issues are worth mentioning. The number of patients in this study was relatively small, particularly with regard to the number of patients who started with insulin therapy during the outpatient consulting period. Larger samples will be required to examine the effect of doctor-patient communication on the mutual decision to commence insulin therapy. Additionally, only one doctor and eighteen patients took part in this study. Therefore, one might argue that, instead of consultation differences, our results are only a reflection of the doctor's working style. However, in a recent study in general practice, doctors' communication behaviours appeared to vary more between patients than between doctors [27]. So the same inter-consultation differences can be expected when examining consecutive consultations from more than one doctor. Nevertheless, further work is needed to examine this and to determine the generalizability of the present results. Moreover, as there appear to be meaningful shifts in communication patterns over time, further research into medical communication should be careful neither to mingle initial and repeat consultations, nor to generalize findings from initial to subsequent consultations. In this respect, there is not only a need for less variability in complaints for which patients go to the doctor [19], but also in the rank order of the consultation. This aspect is likely to be more important in outpatient settings than in general practice, because as virtually all patients in the Netherlands are registered with one general practitioner, most patients will already have a well-established doctor-patient relationship when going to the general practitioner.

In conclusion, the health outcome of outpatients with NIDDM may possibly benefit if the compatibility in communication between doctor and patient during the initial contact were maintained during repeat consultations, i.e. if the doctor continued to present information and advice in an affective way. Post hoc analysis revealed that this will not lead to longer consultations because the correlation between consultation length and proportion of affective utterances by the doctor was small and even tended to be negative $(r=-0.12)$. Further studies may address this issue further by incorporating relevant clinical outcome measures [14].

\section{REFERENCES}

[1] Andersson DKG, Svarsudd K. Long-term glycemic control relates to mortality in NIDDM. Diabetologia 1994;37:A156.

[2] Stamler J, Vaccaro 0. Neaton JD, Wentworth D for the Multiple Risk Factor Intervention Trial Research Group. Diabetes, other risk factors, and 12-year cardiovascular mortality for men screened in the Multiple Risk Factor Intervention Trial. Diabetes Care 1993;16:434- 
Dulmen, A.M. van, Verhaak, P.F.M., Bilo, H.J.G. Shifts in doctor-patient communication during a series of outpatient consultations in non-insulin-dependent diabetes mellitus. Patient Educatien and Counseling: 1997, 30(3), 227-237

444.

[3] Alberti KGMM, Gries FA. Management of non-insulindependent diabetes mellitus in Europe: a consensus view. Diabetic Med 1988:5:275-281.

[4] Glasgow RE, Osteen VL. Evaluating diabetes education. Diabetes Care 1992:15:14231432.

[5] Rottkamp BC, Donohue-Porter P. The role of patient needs and preferences for instructional approaches in self-management of diabetes. Pat Couns Health Educ 1983;4:137-145.

[6] Engel GL. How much longer must medicine's science be bound by a seventeenth century world view? In: White KL, editor. The task of medicine. Menlo Park CA: Kaiser Foundation, 1988.

[7] Bensing JM, Dronkers J. Instrumental and affective aspects of physician behavior. Med Care 1992;30:283- 298.

[8] Miedema K, Veltmaat LJ, Reenders K. Overschakeling op insuline bij NIADM-pationten in de huisartspraktijk. Een onderzoek naar belemmerende factoren (Switching to insulin therapy in NIDDM patients. A study of inhibiting factors in family practice). Huisarts Wet 1995;38:614-617.

[9] Bradley C. Health beliefs and knowledge of patients and doctors in clinical practice and research. Patient Educ Couns 1995;26:99-106.

[10] Murphy E, Kinmonth AL. No symptoms, no problem? Patients' understandings of noninsulin dependent diabetes. Fam Pratt 1995;12:184-192.

[11] Demers RY. Neale AV, Wenzloff NJ, Gronsman KJ, Jaber LA. Glycosylated hemoglobin levels and self-reported stress in adults with diabetes. Behav Med 1989;winter:167-172.

[12] Turkat ID. Glycosylated hemoglobin levels in anxious and nonanxious diabetic patients. Psychosomatics 1982;23:1056-1058.

[13] Gordon D. Fisher SG, Wilson M, Fergus E, Paterson KR, Semple CG. Psychological factors and their relationship to diabetes control. Diabetic Med 1993;10:530- 534.

[14] Ong LML. de Haes JCJM, Hoos AM, Lammes FB.

Doctor-patient communication: a review of the literature. Sot Sci Med 1995;40:903-918.

[15] Boreham P, Gibson D. The informative process in private medical consultations: a preliminary investigation. Sot Sci Med 1978;12:409-416.

[16] Beisecker AE, Beisecker TD. Patient information-seeking behaviors when communicating with doctors. Med Care 1990;28:19-28.

[17] Bradley C. Contributions of psychology to diabetes management. Br J Clin Psycho1 1994;33:11-21.

[IS] Roter D. The Roter method of interaction process analysis. Baltimore: John Hopkins University, 1989.

[19] Bensing JM. Doctor-patient communication and the quality of care. Utrecht: NIVEL, 1991.

[20] van Dulmen AM, Verhaak PFM, Bensing JM. Onderzoek naar de c( mmunicatie tussen specialisten en pat\&ten. Medisch Contact 1996;51:781-783.

[21] Byrne PS, Long BEL. Doctors talking to patients. London: HMSG. 1976.

[22] van der Vlugt MJ, Kruk MR, van Erp AMM. Geuze RH. CAMERA: a system for fast and reliable acquisition of multiple ethological records. Behav Res Methods Instrum Comput 1992;24:147-149.

[23] Wolf MH, Putnam SM, James SA, Stiles WB. The medical interview satisfaction scale: development of a scale to measure patient perceptions of physician behavior. J Behav Med 1978;1:391-401.

[24] Heszen-Klemens, Lapinska E. Doctor-patient interaction, patients' health behavior and effects of treatment. Sot Sci Med 1984;19:9-18.

[25] Kaplan SH, Greenfield S, Ware JE. Assessing the effects of physician-patient interactions on the outcome of chronic disease. Med Care 1989;27:SIIO-5127.

[26] Greene MG, Hoffman S. Charon R, Adelman R. Psychosocial concerns in the medical encounter: a comparison of the interactions of doctors with their old and young patients.

The Geront 198 2 1 - 68.

[27] Bensing JM, Kerssens JJ. van der Pasch M. Patientdirected gaze as a tool for discovering and handling psychosocial problems in general practice. J Nonverb Behav 1995:19:223-242. 
Dulmen, A.M. van, Verhaak, P.F.M., Bilo, H.J.G. Shifts in doctor-patient communication during a series of outpatient consultations in non-insulin-dependent diabetes mellitus. Patient Educatien and Counseling: 1997, 30(3), 227-237

[28] Heer de A. Visser APh, Visschedijk H. De tevredenheid van de dankbare patiUnt in het ziekenhuis. In: Visser APh. editor. Onderzoek naar de tevredenheid van ziekenhuispatiUnten. doel, methode en beleid. Lochem: De Tijdstroom, 1988.

[29] Bertakis KD, Roter D, Putnam S. The relationship of physician medical interview style to patient satisfaction. J Fam Pratt 1991;32:175-181.

[30] Sluijs EM. Patient education in physical therapy. Utrecht: NIVEL, 1991.

[31] Greenfieid S, Kaplan SH, Ware JE, Yano EM, Frank HJL. Patients' participation in medical care. J Gen Intern Med 19883:448-457.

[32] Strull WM, Charles G. Do patients want to participate in medical decision making? J Am Med Assoc 1984:252:2990-2994.

\section{TABLES AND FIGURES}

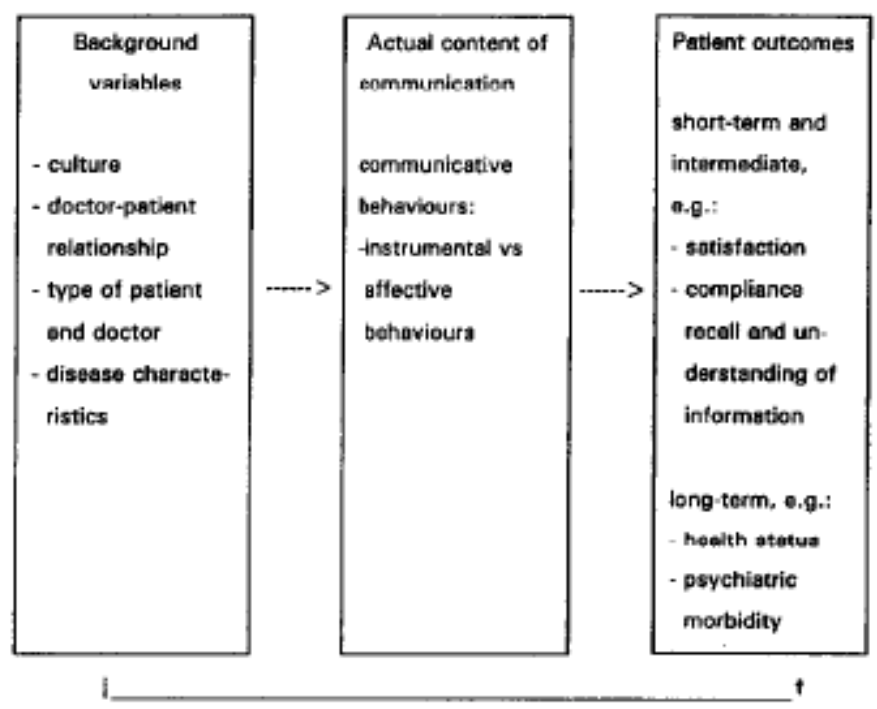

Fig. 1. Theoretical framework showing the relationship of background variables and the process of communication in patient outcomes (after Ong et al. [15]).

Table 1

Overall consultation characteristics

\begin{tabular}{|c|c|c|c|c|c|c|c|}
\hline \multirow[t]{2}{*}{ Variable } & \multirow[t]{2}{*}{ Interactant } & \multicolumn{2}{|c|}{$\begin{array}{l}\text { First } \\
\text { consultation }\end{array}$} & \multicolumn{2}{|c|}{$\begin{array}{l}\text { Second } \\
\text { consultation }\end{array}$} & \multicolumn{2}{|c|}{$\begin{array}{l}\text { Third } \\
\text { consultation }\end{array}$} \\
\hline & & Mean & S.D. & Mean & S.D. & Mean & S.D. \\
\hline Consultation length $(\min )^{\psi}$ & & 26.93 & 6.60 & 10.57 & 4.06 & 8.77 & 2.80 \\
\hline \multirow[t]{2}{*}{$\%$ Speaking time } & Doctor* & 25 & 6 & 50 & 10 & 41 & 14 \\
\hline & Patient & 23 & 10 & 22 & 10 & 25 & 12 \\
\hline$\%$ Non-speaking time & & 22 & 5 & 23 & 9 & 23 & 7 \\
\hline \% Physical exam* & & 27 & 8 & 1 & 4 & 3 & 5 \\
\hline$\%$ Interruptions & & 4 & 5 & 5 & 6 & 8 & 14 \\
\hline \multirow[t]{2}{*}{ Number of utterances } & Doctor ${ }^{6}$ & 202 & 39 & 114 & 39 & 96 & 22 \\
\hline & Patient* & 185 & 45 & 80 & 26 & 74 & 25 \\
\hline \multirow[t]{2}{*}{$\%$ Affective utterances } & Doctor* & 16 & 3 & 15 & 5 & 19 & 6 \\
\hline & Patient* & 14 & 5 & 22 & 6 & 23 & 9 \\
\hline \multirow[t]{2}{*}{$\%$ Instrumental utterances } & Doctor* & 36 & 6 & 44 & 7 & 38 & 10 \\
\hline & Patient* & 33 & 5 & 19 & 5 & 20 & 8 \\
\hline Patient-directed gaze $(\%)^{*}$ & & 58 & 8 & 48 & 13 & 39 & 15 \\
\hline
\end{tabular}

*Significant consultation effect using one-way analysis of variance $(P<0.05)$. 
Dulmen, A.M. van, Verhaak, P.F.M., Bilo, H.J.G. Shifts in doctor-patient communication during a series of outpatient consultations in non-insulin-dependent diabetes mellitus. Patient Educatien and Counseling: 1997, 30(3), 227-237

Table 2

Doctor communication behaviours

\begin{tabular}{|c|c|c|c|c|c|c|}
\hline \multirow[t]{2}{*}{ Variable } & \multicolumn{2}{|c|}{ First consultation } & \multicolumn{2}{|c|}{ Second consultation } & \multicolumn{2}{|c|}{ Third consultation } \\
\hline & Mean & S.D. & Mean & S.D. & Mean & S.D. \\
\hline \multicolumn{7}{|l|}{ Roter Interaction Analysis (\%) } \\
\hline \multicolumn{7}{|l|}{ Affective } \\
\hline Social behaviour & 2.40 & 1.92 & 3.41 & 2.64 & 4.52 & 5.41 \\
\hline Agreements* & 6.56 & 2.34 & 4.41 & 2.50 & 5.25 & 2.55 \\
\hline Paraphrases* & 3.11 & 1.01 & 1.92 & 1.41 & 2.18 & 1.46 \\
\hline Reflections & 0.76 & 0.63 & 0.77 & 0.72 & 0.80 & 0.84 \\
\hline Concerns & 0.84 & 0.78 & 0.76 & 0.75 & 1.14 & 1.77 \\
\hline Reassurances* & 2.50 & 1.20 & 3.81 & 1.87 & 5.27 & 2.85 \\
\hline Disagreements & 0.09 & 0.20 & 0.19 & 0.48 & 0.17 & 0.35 \\
\hline \multicolumn{7}{|l|}{ Instrumental } \\
\hline Orientations & 2.86 & 0.85 & 3.85 & 2.30 & 2.85 & 2.28 \\
\hline Requests for clarification* & 2.35 & 1.25 & 1.38 & 0.86 & 2.54 & 1.40 \\
\hline Medical questions" & 13.50 & 4.60 & 3.07 & 2.00 & 3.22 & 2.63 \\
\hline Psychosocial questions & 0.94 & 0.75 & 0.64 & 1.43 & 0.36 & 0.55 \\
\hline Medical information* & 12.54 & 6.01 & 27.89 & 8.27 & 21.71 & 10.46 \\
\hline Psychosocial information & 0.54 & 0.80 & 0.31 & 0.64 & 0.31 & 0.54 \\
\hline Medical counseling* & 1.64 & 0.99 & 4,45 & 3.20 & 5.53 & 3.31 \\
\hline Psychosocial counseling & 0.30 & 0.38 & 0.47 & 1.07 & 0.48 & 0.80 \\
\hline Administrative & 1.55 & 1.81 & 1.46 & 1.16 & 0.79 & 1.26 \\
\hline \multicolumn{7}{|l|}{ Patient-centredness (1-5) } \\
\hline Diagnostic phase & 3.17 & 0.38 & 3.22 & 0.54 & 3.33 & 0.59 \\
\hline Therapeutic phase* & 2.89 & 0.47 & 3.56 & 0.51 & 3.33 & 0.77 \\
\hline \multicolumn{7}{|l|}{ Affect scales (1-6) } \\
\hline Irritation & 1.72 & 0.83 & 1.44 & 0.86 & 1.39 & 0.70 \\
\hline Nervousness & 1.28 & 0.67 & 1.28 & 0.46 & 1.28 & 0.46 \\
\hline Interest & 4.50 & 0.62 & 4.67 & 0.84 & 4.61 & 0.78 \\
\hline Warmth & 4.78 & 0.65 & 4.72 & 1.13 & 4.89 & 0.58 \\
\hline
\end{tabular}

* Significant consultation effect using one-way analysis of variance $(P<0.05)$.

\begin{tabular}{|c|c|c|c|c|c|c|}
\hline \multirow[t]{2}{*}{ Variable } & \multicolumn{2}{|c|}{ First consultation } & \multicolumn{2}{|c|}{ Second consultation } & \multicolumn{2}{|c|}{ Third consultation } \\
\hline & Mean & S.D. & Mean & S.D. & Mean & S.D. \\
\hline \multicolumn{7}{|l|}{ Roter Interaction Analysis (\%) } \\
\hline \multicolumn{7}{|l|}{ Affective } \\
\hline Social behaviour & 3.66 & 3.33 & 3.47 & 3.43 & 5.25 & 6.36 \\
\hline Agreements* & 8.55 & 4.01 & 14.58 & 5.14 & 13.44 & 5.50 \\
\hline Paraphrases* & 0.68 & 0.57 & 1.86 & 1.76 & 1.42 & 1.53 \\
\hline Reflections & 0.00 & 0.00 & 0.00 & 0.00 & 0.09 & 0.30 \\
\hline Concerns & 0.93 & 1.21 & 1.46 & 2.80 & 1.60 & 1.44 \\
\hline Reassurances & 0.33 & 0.37 & 0.87 & 1.41 & 0.90 & 1.37 \\
\hline Disagreements & 0.17 & 0.29 & 0.10 & 0.26 & 0.12 & 0.31 \\
\hline \multicolumn{7}{|l|}{ Instrumental } \\
\hline Orientations & 0.35 & 0.50 & 0.38 & 0.48 & 0.46 & 0.52 \\
\hline Requests for understanding & 0.80 & 0.53 & 0.89 & 0.96 & 0.67 & 0.85 \\
\hline Medical questions* & 0.70 & 0.67 & 2.44 & 1.37 & 1.85 & 1.49 \\
\hline Psychosocial questions & 0.00 & 0.00 & 0.11 & 0.46 & 0.06 & 0.17 \\
\hline Medical information* & 26.51 & 4.18 & 11.68 & 5.39 & 14.04 & 6.27 \\
\hline Psychosocial information* & 4.06 & 2.95 & 1.98 & 2.15 & 2.35 & 2.94 \\
\hline Medical counseling & 0.12 & 0.19 & 0.08 & 0.24 & 0.09 & 0.27 \\
\hline Psychosocial counseling & 0.03 & 0.09 & 0.00 & 0.00 & 0.00 & 0.00 \\
\hline Administrative & 0.64 & 0.82 & 1.33 & 1.74 & 0.54 & 1.00 \\
\hline \multicolumn{7}{|l|}{ Affect scales $(1-6)$} \\
\hline Irritation & 1.06 & 0.24 & 1.06 & 0.24 & 1.28 & 0.57 \\
\hline Nervousness & 2.06 & 0.99 & 2.33 & 1.19 & 2.11 & 0.90 \\
\hline Interest & 4.11 & 0.68 & 4.33 & 0.59 & 4.61 & 0.92 \\
\hline Warmth & 4.33 & 0.84 & 3.94 & 1.11 & 4.17 & 0.62 \\
\hline
\end{tabular}

*Significant consultation effect using onc-way anklysis of variance $(P<0.05)$. 
Dulmen, A.M. van, Verhaak, P.F.M., Bilo, H.J.G. Shifts in doctor-patient communication during a series of outpatient consultations in non-insulin-dependent diabetes mellitus. Patient Educatien and Counseling: 1997, 30(3), 227-237

Table 4

Medical interview satisfaction (MISS) scores

\begin{tabular}{|c|c|c|c|c|c|c|c|c|c|}
\hline \multirow[t]{2}{*}{ Subscale* } & \multicolumn{3}{|c|}{ First consultation } & \multicolumn{3}{|c|}{ Second consuitation } & \multicolumn{3}{|c|}{ Third consultation } \\
\hline & Mean & S.D. & $N$ & Mean & S.D. & $N$ & Mean & S.D. & $N$ \\
\hline Cognitive & 4.01 & 0.46 & 18 & 3.91 & 0.46 & 13 & 3.93 & 0.49 & 13 \\
\hline Affective & 4.02 & 0.49 & 18 & 4,02 & 0.46 & 13 & 3.91 & 0.44 & 13 \\
\hline Behavioural & 4.18 & 0.52 & 18 & 3.87 & 0.43 & 13 & 3.90 & 0.52 & 13 \\
\hline
\end{tabular}

*Possible score range $1-5$, higher scores indicating higher satisfaction. 